\title{
Merging Photoredox with 1,2-Metallate Rearrangements: The Photochemical Alkylation of Vinyl Boronate Complexes
}

\author{
Mattia Silvi, Christopher Sandford, and Varinder K. Aggarwal*i) \\ School of Chemistry, University of Bristol, Cantock's Close, Bristol BS8 1TS, United Kingdom \\ Supporting Information
}

\begin{abstract}
Vinyl boronates react with electron-deficient alkyl iodides in the presence of visible light to give boronic esters in which two new $\mathrm{C}-\mathrm{C}$ bonds have been created. The reaction occurs by radical addition of an electron-deficient alkyl radical to the vinyl boronate followed by electron transfer with another molecule of alkyl iodide, continuing the chain, and triggering a 1,2metalate rearrangement. In a number of cases, the use of a photoredox catalyst enhances yields significantly. The scope of the radical precursor includes $\alpha$-iodo ketones, esters, nitriles, primary amides, $\alpha$-fluorinated halo-acetates and perfluoroalkyl iodides.
\end{abstract}

Cince its discovery over 50 years ago, the 1,2-metalate $\checkmark$ rearrangement of boronate complexes possessing $\alpha$-leaving groups (Scheme 1a, Matteson reaction) has been developed and refined into a powerful and versatile, substrate-controlled, asymmetric methodology, which has been widely used in synthesis. ${ }^{1}$ In the past decade, we have established a suite of related reagent-controlled homologations of boronic esters. ${ }^{2}$ This methodology allowed us to develop iterative processes that enable the conversion of simple starting materials into complex molecules without intermediate purification, a strategy that was applied to the synthesis of natural ${ }^{3}$ and non-natural products. ${ }^{4}$ Over the same period, photoredox catalysis has emerged as a tremendously versatile platform for organic synthesis, enabling reactive radical centers to be generated at specific positions in organic molecules under exceptionally mild conditions. ${ }^{5,6}$ One of the key features of photoredox catalysis is the potential to crossover from a radical to a polar pathway ${ }^{7}$ during the overall catalytic process. For example, in photoredox olefin functionalizations with electrophilic radicals, ${ }^{8}$ single-electron transfer (SET) from radical 4 generates cation 5 , which can be trapped by nucleophiles to afford adducts 6 (Scheme 1b).9 We considered the possibility of merging the features of photoredox reactions with 1,2-metalate rearrangements, two contemporary synthetic strategies that are currently unconnected. Specifically, we reasoned that related reactions of vinyl boronates 7 with electrophilic radicals 8 would lead to a new radical anion 9 that might undergo single-electron oxidation and trigger a 1,2metalate rearrangement, generating diversely functionalized boronic esters 10 (Scheme 1c). ${ }^{10}$ This strategy, which was ultimately successful, provides a novel three-component coupling reaction where two new $\mathrm{C}-\mathrm{C}$ bonds are formed in one step, rapidly building up molecular complexity while retaining the highly versatile boronic ester moiety. During the
Scheme 1. (a) 1,2-Metallate Rearrangements, (b) Photoredox Radical-Polar Crossover Reactions, (c) This Work: Merging Photoredox with 1,2-Metallate Rearrangements

a)

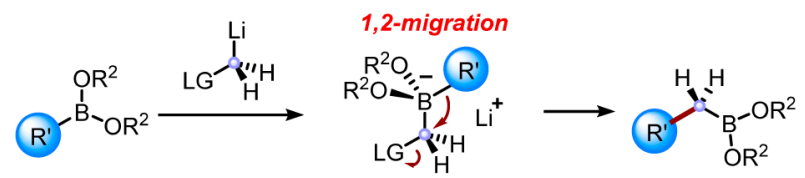

b) Photoredox Radical-Polar Crossover Functionalizations
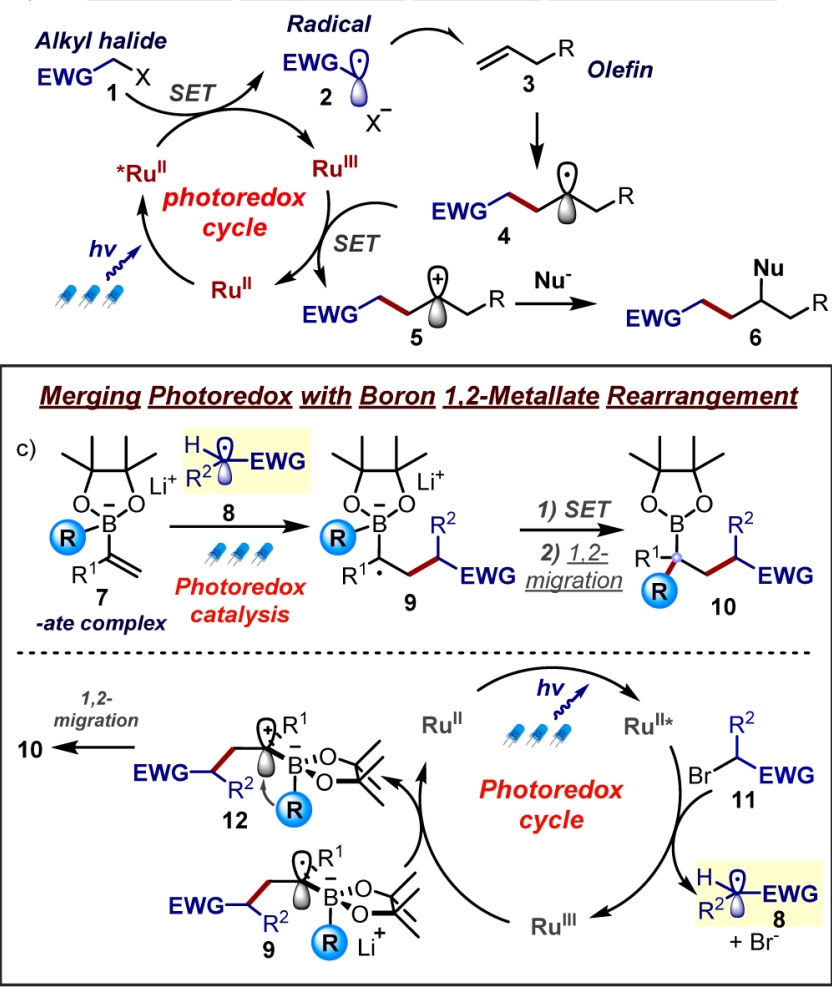

preparation of this manuscript, Studer and co-workers reported a related radical three-component coupling reaction of alkyl iodides and vinyl boronate complexes, utilizing triethylborane/ air for radical generation. ${ }^{11}$

We began our studies by exploring the reaction between vinyl boronates and phenacyl halides and tested various solvents and metal catalysts under visible-light irradiation (Table 1). Phenacyl halides were selected as radical precursors owing to their well-

Received: March 14, 2017

Published: April 12, 2017 
Table 1. Optimization Studies
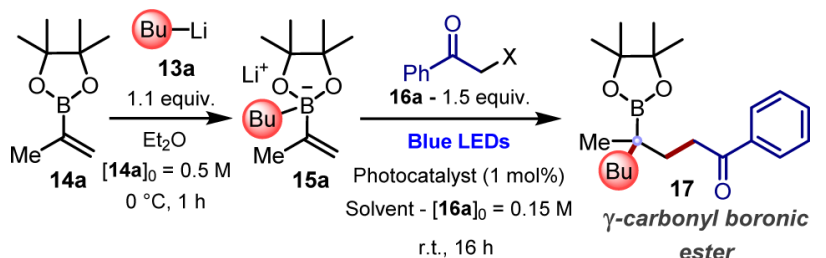

r.t., $16 \mathrm{~h}$

ester

$\begin{array}{cl}\text { entry }^{a} & \text { solvent } \\ 1 & \text { DMSO } \\ 2 & \text { DMSO } \\ 3 & \text { DMSO } \\ 4 & \text { DMSO } \\ 5 & \text { THF } \\ 6 & \text { DMI } \\ 7^{c} & \text { DMI } \\ 8^{c} & \text { DMI } \\ 9^{c, d} & \text { DMI }\end{array}$

\begin{tabular}{ll} 
X & \multicolumn{1}{c}{ photocatalyst } \\
$\mathrm{Cl}$ & $\mathrm{Ru}(\text { bpy })_{3} \mathrm{Cl}_{2} \cdot 6 \mathrm{H}_{2} \mathrm{O}$ \\
$\mathrm{Br}$ & $\mathrm{Ru}(\text { bpy })_{3} \mathrm{Cl}_{2} \cdot 6 \mathrm{H}_{2} \mathrm{O}$ \\
$\mathrm{Br}$ & $\mathrm{Ir}(\text { ppy })_{3}$ \\
$\mathrm{I}$ & $\mathrm{Ru}(\text { bpy })_{3} \mathrm{Cl}_{2} \cdot 6 \mathrm{H}_{2} \mathrm{O}$ \\
$\mathrm{I}$ & $\mathrm{Ru}(\mathrm{bpy})_{3} \mathrm{Cl}_{2} \cdot 6 \mathrm{H}_{2} \mathrm{O}$ \\
$\mathrm{I}$ & $\mathrm{Ru}(\mathrm{bpy})_{3} \mathrm{Cl}_{2} \cdot 6 \mathrm{H}_{2} \mathrm{O}$ \\
$\mathrm{I}$ & $\mathrm{Ru}(\mathrm{bpy})_{3} \mathrm{Cl}_{2} \cdot 6 \mathrm{H}_{2} \mathrm{O}$ \\
I & none \\
I & none
\end{tabular}

$17(\%)^{b}$

traces

57

57

80

38

85

$86(85)$

$87(88)$

15

${ }^{a}$ Unless otherwise noted, all the reactions were carried out under a nitrogen atmosphere, using Schlenk techniques, on a $0.15 \mathrm{mmol}$ scale. After boronate complex formation, solvent exchange to the selected solvent was performed. ${ }^{{ }_{1}} \mathrm{H}$ NMR yield using 1,3,5-trimethoxybenzene as an internal standard; yield of isolated product based on a $0.3 \mathrm{mmol}$ scale reaction is given in parentheses. ${ }^{c}$ Reaction carried out by adding a DMI solution of iodoacetophenone to the ethereal suspension of boronate complex. ${ }^{d}$ Reaction carried out in the dark.

established tendency to readily undergo one-electron reduction generating stabilized, electrophilic $\alpha$-carbonyl radicals, ${ }^{12}$ and because they have been used in photoredox-mediated reactions. ${ }^{5 a}$ For our optimization studies, boronate complex 15a was generated in situ by treating the boronic ester 14a with $n$-butyllithium in $\mathrm{Et}_{2} \mathrm{O}$. After solvent removal, a solution of phenacyl halide and the photocatalyst were added to the vessel and the mixture irradiated with blue light.

Although phenacyl chloride was not a good substrate for our reaction (entry 1), we were pleased to find that subjecting the corresponding bromide to our reaction conditions in the presence of $\mathrm{Ru}(\mathrm{bpy})_{3} \mathrm{Cl}_{2} \cdot 6 \mathrm{H}_{2} \mathrm{O}$ afforded boronic ester 17 in $57 \%$ yield (entry 2 ). The use of the more reducing photocatalyst $\operatorname{Ir}(\text { ppy })_{3}$ gave similar results (entry 3 ). Gratifyingly, simply by replacing phenacyl bromide with the corresponding iodide, the yield improved to $80 \%$ (entry 4 ). The improvement of yield going from $\mathrm{Cl}$ to $\mathrm{Br}$ to I follows the increasing ease of oneelectron reduction along the series. ${ }^{12,13}$ Solvent effects were also explored and further improvements were observed by switching from DMSO to 1,3-dimethyl-2-imidazolidinone (DMI, entry 6). We also found that $\mathrm{Et}_{2} \mathrm{O}-\mathrm{DMI}$ mixtures could be used (entry 7), simplifying the reaction set up: after formation of the boronate complex in ether, a DMI solution of the radical precursor was added to the boronate complex, avoiding solvent exchange. However, and much to our surprise, a control experiment without the photocatalyst and just irradiation with blue LEDs afforded the product in a similar yield (88\%, entry 8). ${ }^{14} \mathrm{~A}$ further control experiment (entry 9) showed that light was essential as little product was obtained in the dark.

With optimum reaction conditions established, we tested a range of different boronate complexes (Scheme 2). Boronate complexes obtained by treating boronic ester 14a with $n$ butyllithium, iso-propyllithium or tert-butyllithium all reacted efficiently (Scheme 2, 17-19), demonstrating that the level of steric hindrance around the boron center does not significantly
Scheme 2. Scope of Boronates and Phenacyl Iodides ${ }^{a}$

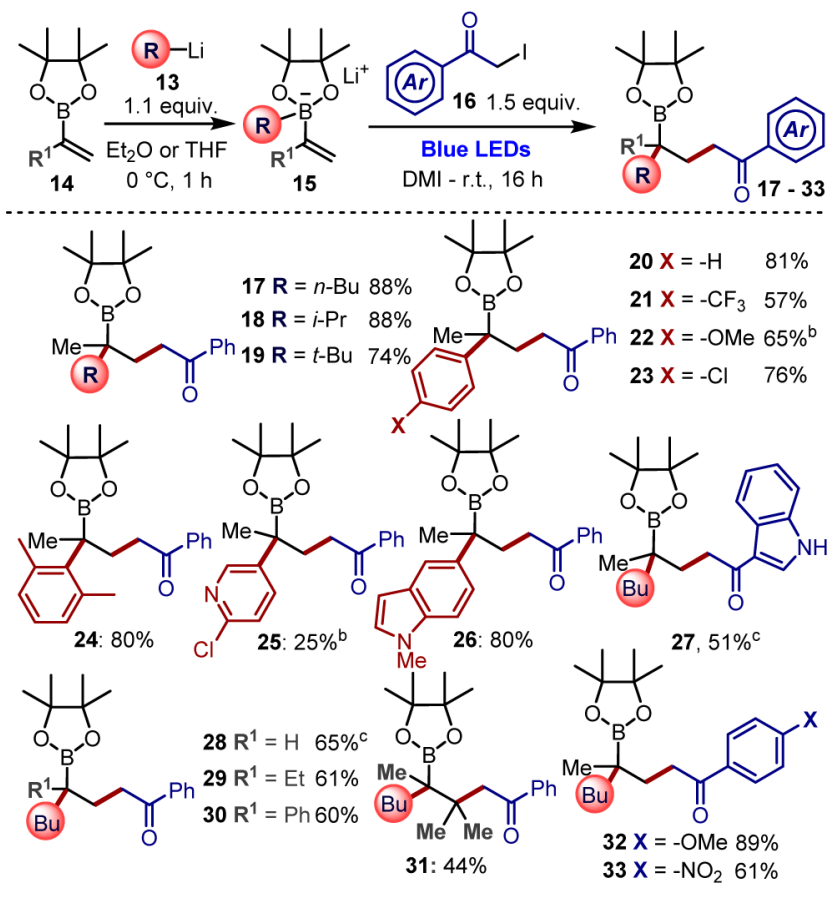

${ }^{a}$ Reactions were carried out under a nitrogen atmosphere, using Schlenk techniques on a $0.3 \mathrm{mmol}$ scale; yields after chromatographic purification. ${ }^{b}$ Yield of the corresponding alcohol following $\mathrm{H}_{2} \mathrm{O}_{2}$ / $\mathrm{NaOH}$ oxidation. ${ }^{c} 1 \mathrm{~mol} \%$ of $\mathrm{Ru}(\mathrm{bpy})_{3} \mathrm{Cl}_{2} \cdot 6 \mathrm{H}_{2} \mathrm{O}$ was used.

impact on the radical addition, subsequent oxidation or 1,2migration steps. A range of aryllithiums of different steric and electronic properties worked well (20-24). Organolithiums generated from heteroaromatics could also be used: the 5indolyl-substituted compound $\mathbf{2 6}$ was obtained with high yield, although the 3-pyridyl compound 25 was obtained in lower yield. Variation of the $\alpha$-substituent $\left(\mathrm{R}^{1}\right)$ of the vinyl boronate (products 28-30) and a fully substituted vinyl moiety (product 31) were tolerated, although the unsubstituted vinyl boronate $\left(\mathrm{R}^{1}=\mathrm{H}\right.$, product 28$)$ required the use of a photocatalyst to achieve high yields (37\% yield in the absence of $\mathrm{Ru}(\text { bpy })_{3} \mathrm{Cl}_{2}$. $6 \mathrm{H}_{2} \mathrm{O}$ ). The scope of the phenacyl iodide radical precursors was also explored: electron-rich and electron-deficient aromatic groups (products 32-33), as well as an $\mathrm{N}-\mathrm{H}$ indole moiety (product 27), were successfully introduced.

We then tested a more diverse range of alkyl halide radical precursors (Scheme 3). We were delighted to find that subjecting aliphatic $\alpha$-iodo ketones (preformed in the reaction medium by treatment of the corresponding bromides or chlorides with stoichiometric NaI, see SI and vide infra) to our reaction conditions afforded the desired compounds in high yield (compounds 35-36). Other functionalities such as esters, nitriles and, remarkably, primary amides could also be employed affording the desired products in good to excellent yields (products 37-39). $\alpha$-Fluorinated halo-acetates and perfluoroalkyl iodides, ${ }^{8,15,16}$ including $\mathrm{CF}_{3} \mathrm{I}{ }^{17}$ were also successfully employed, affording the corresponding fluorinated tertiary boronic esters in good to excellent yields (products 40-43), although the use of a photocatalyst was found to be necessary in most cases in order to achieve good reaction efficiency. Diethyl bromomalonate, an efficient reagent for atom-transfer radical additions (ATRA) to olefins, ${ }^{8}$ was also a competent radical 
Scheme 3. Scope of Radical Precursors ${ }^{a}$

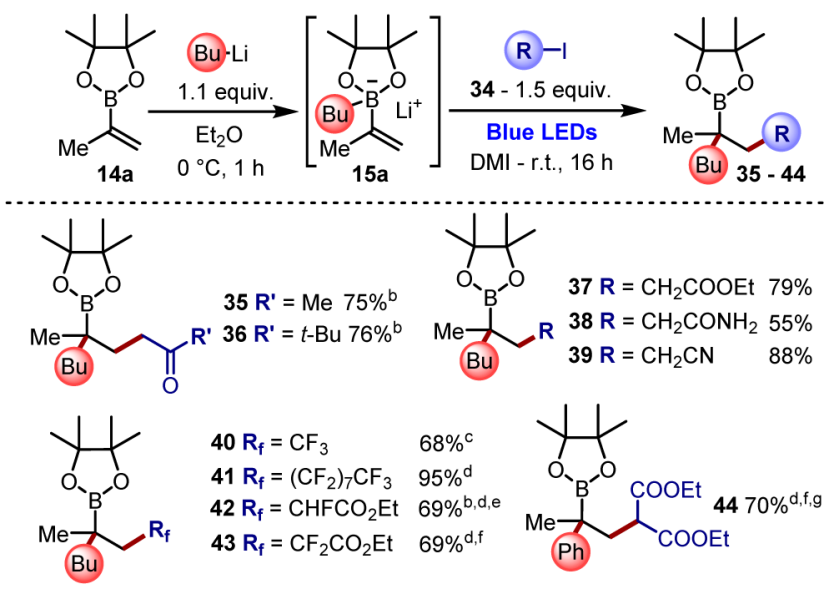

${ }^{a}$ Reactions were carried out under a nitrogen atmosphere, using Schlenk techniques, on a $0.3 \mathrm{mmol}$ scale; yields after chromatographic purification. ${ }^{b}$ Reaction carried out starting from the corresponding bromide or chloride, premixed with $\mathrm{NaI}$ prior to addition (see SI). ${ }^{c} 5$ equiv of $\mathrm{CF}_{3} \mathrm{I} \cdot 2 \mathrm{DMSO}$ were used. ${ }^{d} 1 \mathrm{~mol} \%$ of $\mathrm{Ru}(\mathrm{bpy})_{3} \mathrm{Cl}_{2} \cdot 6 \mathrm{H}_{2} \mathrm{O}$ was added. ${ }^{e} 2: 1$ d.r. ${ }^{f}$ Reaction carried out starting from the corresponding bromide. ${ }^{g}$ Boronate complex derived from phenyllithium.

precursor furnishing, in the presence of a ruthenium photocatalyst, boronic ester $\mathbf{4 4}$ in high yield.

The products from these reactions are noteworthy. For example, although ample methods are available for the synthesis of $\beta$-carbonyl boronic esters (e.g., by conjugate addition to Michael acceptors), ${ }^{18}$ there are few examples for the synthesis of $\gamma$-carbonyl boronic esters ${ }^{19}$ that are now easily accessible using the current methodology. Furthermore, it is not possible to create compounds like $\mathbf{4 0}$ by existing metalate rearrangements since intermediate boronate complexes with $\beta$-leaving groups undergo elimination instead of 1,2-migration. ${ }^{20}$

Next, we conducted further experiments to probe the reaction mechanism. Carrying out the reaction in the presence of a nitroxyl radical (TEMPO) completely shut down the reaction, suggesting that a radical mechanism is operative (Scheme 4).

Scheme 4. Control Experiments

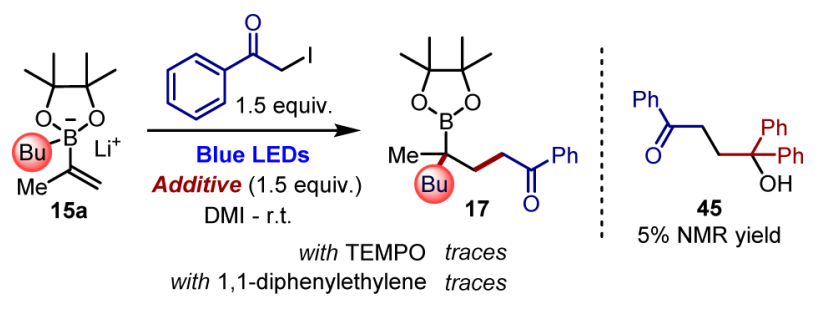

Furthermore, when the reaction was carried out in the presence of a styryl radical trap (1,1-diphenylethylene), ${ }^{21}$ addition to the boronate was suppressed and adduct 45 was observed in the crude reaction mixture. ${ }^{22}$ This product could arise from addition of the phenacyl radical to the radical trap ${ }^{23}$ followed by either oxidation of the stabilized benzylic radical generated, or hydrolysis of the benzyl iodide atom-transfer product upon workup.

To gain insight into the mechanism of the photoinitiation event, we conducted UV/vis absorption analysis of both the boronate complex and iodoacetophenone separately and then combined; however, no new bands in the visible region were observed, indicating that a ground-state charge-transfer complex was not formed in solution. ${ }^{14 a, b}$ We did observe very low residual visible-light absorption of the iodoacetophenone (see SI for further details), which we postulate is the photoinitiation event. Thus, the mechanism proposed involves homolytic cleavage of the alkyl iodide by visible light, generating the electrophilic alkyl radical 46, ${ }^{23,24}$ which reacts with the electron-rich vinyl boronate complex 15a to form boronate radical 47 (Scheme 5). This

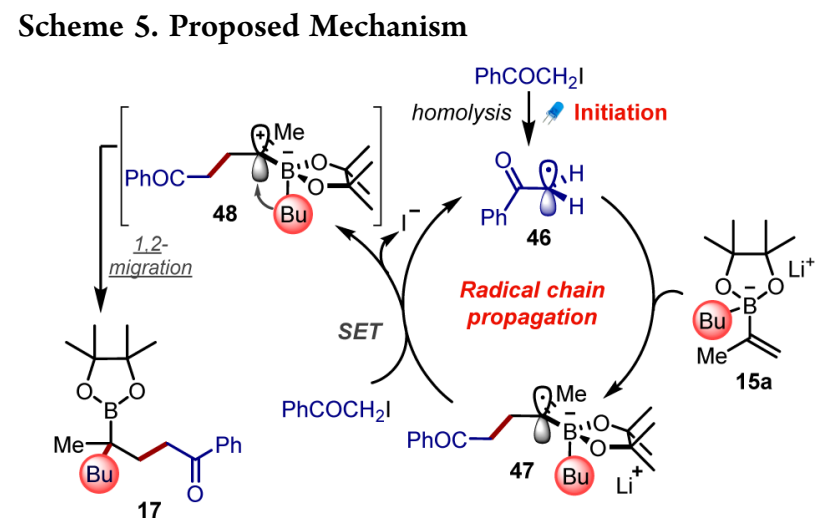

electron-rich radical anion then undergoes facile single-electron oxidation (or iodine atom transfer, not shown $)^{25}$ with another molecule of alkyl iodide, ${ }^{11,26}$ thus triggering rapid (or concerted $)^{27}$ 1,2-metalate rearrangement to afford the product 17. The process also releases a new $\alpha$-carbonyl radical 46, thereby feeding a radical chain propagation pathway. We have found that for the reactions affording compounds 27, 28 and 41-44, the addition of a $\mathrm{Ru}$ photocatalyst was necessary to achieve high yields. In these cases, in the absence of photocatalyst, the innate radical chain is likely to be inefficient, stemming from slow initiation or slow electron/atom transfer. However, in these particular cases, a ruthenium photocatalyst is able to mediate these steps, leading to high yields.

Finally, because alkyl iodides are often not commercially available, are light- and air sensitive, and are severe lachrymators, we sought to generate them in situ from the corresponding bromides with $\mathrm{NaI}$. Subjecting phenacyl bromide to our reaction conditions in the presence of sodium iodide $(20 \mathrm{~mol} \%)$, we were delighted to observe the formation of the desired compound in $78 \%$ yield, further improving the efficiency and sustainability of our approach (Scheme 6). Thus, two pathways are available from the bromoketone: use of $1 \mathrm{~mol} \%$ of the $\mathrm{Ru}$ photosensitizer or $20 \mathrm{~mol} \%$ of $\mathrm{NaI}$.

In conclusion, after over 50 years of 1,2-metalate rearrangements involving $\alpha$-leaving groups, we have discovered a novel trigger mechanism involving oxidation of an $\alpha$-boronate radical. This radical species can be generated from a halide and a vinyl

Scheme 6. Using NaI for Bromoacetophenone Activation

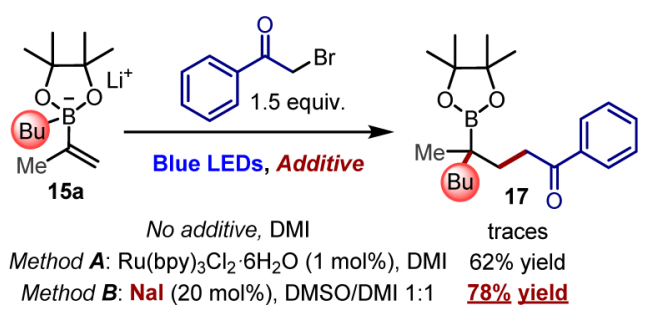


boronate by photoredox, visible-light-induced activation or by Studer's Et ${ }_{3}$ B/air protocol. ${ }^{11}$ The collective methods cover vast substrate scope providing a novel, efficient and atom-economic three-component coupling reaction. Furthermore, many of the products are simply not accessible through traditional 1,2metalate rearrangements, thereby opening up new chemical space.

\section{ASSOCIATED CONTENT}

\section{S Supporting Information}

The Supporting Information is available free of charge on the ACS Publications website at DOI: 10.1021/jacs.7b02569.

Detailed experimental procedure and characterization data for new compounds (PDF)

\section{AUTHOR INFORMATION}

\section{Corresponding Author}

*v.aggarwal@bristol.ac.uk

\section{ORCID}

Varinder K. Aggarwal: 0000-0003-0344-6430

Notes

The authors declare no competing financial interest.

\section{ACKNOWLEDGMENTS}

We thank the University of Bristol for financial support. M.S. thanks the EU for H-2020 Marie Skłodowska-Curie Fellowship (grant no. 744242). We thank Dr. Eddie Myers for useful discussions.

\section{REFERENCES}

(1) (a) Matteson, D. S.; Mah, R. W. H. J. Am. Chem. Soc. 1963, 85, 2599. (b) Matteson, D. S. Acc. Chem. Res. 1988, 21, 294. (c) Matteson, D. S. Tetrahedron 1998, 54, 10555. (d) Matteson, D. S. J. Org. Chem. 2013, 78, 10009.

(2) (a) Stymiest, J. L.; Dutheuil, G.; Mahmood, A.; Aggarwal, V. K. Angew. Chem., Int. Ed. 2007, 46, 7491. (b) Stymiest, J. L.; Bagutski, V.; French, R. M.; Aggarwal, V. K. Nature 2008, 456, 778. (c) Thomas, S. P.; French, R. M.; Jheengut, V.; Aggarwal, V. K. Chem. Rec. 2009, 9, 24. (d) Leonori, D.; Aggarwal, V. K. Acc. Chem. Res. 2014, 47, 3174.

(3) (a) Rasappan, R.; Aggarwal, V. K. Nat. Chem. 2014, 6, 810. (b) Balieu, S.; Hallett, G. E.; Burns, M.; Bootwicha, T.; Studley, J.; Aggarwal, V. K. J. Am. Chem. Soc. 2015, 137, 4398. (c) Varela, A.; Garve, L. K. B.; Leonori, D.; Aggarwal, V. K. Angew. Chem., Int. Ed. 2017, 56, 2127.

(4) Burns, M.; Essafi, S.; Bame, J. R.; Bull, S. P.; Webster, M. P.; Balieu, S.; Dale, J. W.; Butts, C. P.; Harvey, J. N.; Aggarwal, V. K. Nature 2014, $513,183$.

(5) (a) Nicewicz, D. A.; MacMillan, D. W. C. Science 2008, 322, 77. (b) Ischay, M. A.; Anzovino, M. E.; Du, J.; Yoon, T. P. J. Am. Chem. Soc. 2008, 130, 12886. (c) Narayanam, J. M. R.; Tucker, J. W.; Stephenson, C. R. J. J. Am. Chem. Soc. 2009, 131, 8756.

(6) (a) Prier, C. K.; Rankic, D. A.; MacMillan, D. W. C. Chem. Rev. 2013, 113, 5322. (b) Shaw, M. H.; Twilton, J.; MacMillan, D. W. C. J. Org. Chem. 2016, 81, 6898. (c) Goddard, J.-P.; Ollivier, C.; Fensterbank, L. Acc. Chem. Res. 2016, 49, 1924. (d) Staveness, D.; Bosque, I.; Stephenson, C. R. J. Acc. Chem. Res. 2016, 49, 2295.

(7) Murphy, J. A. In Radicals in Organic Synthesis; Renaud, P., Sibi, M. P., Eds.; Wiley-VCH: Weinheim, 2001; pp 298-314.

(8) (a) Nguyen, J. D.; Tucker, J. W.; Konieczynska, M. D.; Stephenson, C. R. J. J. Am. Chem. Soc. 2011, 133, 4160. (b) Wallentin, C. J.; Nguyen, J. D.; Finkbeiner, P.; Stephenson, C. R. J. J. Am. Chem. Soc. 2012, 134, 8875 .

(9) For selected reviews: (a) Koike, T.; Akita, M. Acc. Chem. Res. 2016, 49, 1937. (b) Courant, T.; Masson, G. J. Org. Chem. 2016, 81, 6945. For examples involving skeletal rearrangements: (c) Sahoo, B.; Li, J. L.;
Glorius, F. Angew. Chem., Int. Ed. 2015, 54, 11577. (d) Honeker, R.; Garza-Sanchez, R. A.; Hopkinson, M. N.; Glorius, F. Chem. - Eur. J. 2016, 22, 4395. (e) Bergonzini, G.; Cassani, C.; Lorimer-Olsson, H.; Hörberg, J.; Wallentin, C. Chem. - Eur. J. 2016, 22, 3292. (f) Huang, H.L.; Yan, H.; Yang, C.; Xia, W. Chem. Commun. 2015, 51, 4910. (g) Li, Y.; Liu, B.; Ouyang, X.-H.; Song, R.-J.; Li, J.-H. Org. Chem. Front. 2015, 2, 1457.

(10) We recently reported the addition of $\mathrm{CF}_{3}$ radicals to furyl-derived boronate complexes: Wang, Y.; Noble, A.; Sandford, C.; Aggarwal, V. K. Angew. Chem., Int. Ed. 2017, 56, 1810.

(11) Kischkewitz, M.; Okamoto, K.; Mück-Lichtenfeld, C.; Studer, A. Science 2017, 355, 936.

(12) Andrieux, C. P.; Savéant, J. M.; Tallec, A.; Tardivel, R.; Tardy, C. J. Am. Chem. Soc. 1997, 119, 2420.

(13) Parrish, J. D.; Shelton, D. R.; Little, R. D. Org. Lett. 2003, 5, 3615.

(14) For other examples of photoredox reactions occurring efficiently even in the absence of photocatalysts: (a) Arceo, E.; Jurberg, I. D.; Alvarez-Fernández, A.; Melchiorre, P. Nat. Chem. 2013, 5, 750. (b) Beatty, J. W.; Douglas, J. J.; Miller, R.; McAtee, R. C.; Cole, K. P.; Stephenson, C. R. J. Chem. 2016, 1, 456. (c) Silvi, M.; Arceo, E.; Jurberg, I. D.; Cassani, C.; Melchiorre, P. J. Am. Chem. Soc. 2015, 137, 6120. (d) Sahoo, B.; Hopkinson, M. N.; Glorius, F. Angew. Chem., Int. Ed. 2015, 54, 15545. (e) Cecere, G.; König, C. M.; Alleva, J. L.; MacMillan, D. W. C. J. Am. Chem. Soc. 2013, 135, 11521.

(15) (a) Müller, K.; Faeh, C.; Diederich, F. Science 2007, 317, 1881 (b) Purser, S.; Moore, P. P.; Swallow, S.; Gouverneur, V. Chem. Soc. Rev. 2008, 37, 320. (c) Hagmann, W. K. J. Med. Chem. 2008, 51, 4359.

(16) Chatterjee, T.; Iqbal, N.; You, Y.; Cho, E. J. Acc. Chem. Res. 2016, 49, 2284.

(17) (a) Ma, J.-A.; Cahard, D. J. Fluorine Chem. 2007, 128, 975. (b) Studer, A. Angew. Chem., Int. Ed. 2012, 51, 8950. (c) Sladojevich, F.; McNeill, E.; Börgel, J.; Zheng, S.-L.; Ritter, T. Angew. Chem., Int. Ed. 2015, 54, 3712 .

(18) (a) Lee, S.; Yun, J. In Synthesis and Application of Organoboron Compounds; Fernández, E., Whiting, A., Eds.; Springer International Publishing: Cham, 2015; pp 73-92. (b) Lillo, V.; Bonet, A.; Fernandez, E. Dalton Trans. 2009, 2899. (c) Schiffner, J. A.; Müther, K.; Oestreich, M. Angew. Chem., Int. Ed. 2010, 49, 1194.

(19) (a) Pereira, S.; Srebnik, M. Tetrahedron Lett. 1995, 36, 1805. (b) Dudnik, A. S.; Fu, G. C. J. Am. Chem. Soc. 2012, 134, 10693. (c) Lo, J. C.; Gui, J.; Yabe, Y.; Pan, C.-M.; Baran, P. S. Nature 2014, 516, 343. (20) (a) Matteson, D. S. J. Organomet. Chem. 1999, 581, 51. (b) Fawcett, A.; Nitsch, D.; Ali, M.; Bateman, J. M.; Myers, E. L.; Aggarwal, V. K. Angew. Chem., Int. Ed. 2016, 55, 14663.

(21) For selected examples of the use of 1,1-diphenylethylene as a radical inhibitor: (a) Lubinkowski, J. J.; Knapczyk, J. W.; Calderon, J. L.; Petit, L. R.; McEwen, W. E. J. Org. Chem. 1975, 40, 3010. (b) Seo, H.; Katcher, M. H.; Jamison, T. F. Nat. Chem. 2016, [advance online publication], doi: $10.1038 /$ nchem. 2690 .

(22) An analogous byproduct was observed by Glorius and co-workers in the radical trifluoromethylthiolation of 1,1-diphenylethylene, due to the oxidation of the intermediate benzylic radical and trapping by solvent or adventitious water. See ref $9 \mathrm{~d}$.

(23) Trapping of phenacyl radicals by 1,1-diphenylethylene has been observed to be extremely fast: Jovanovic, S. V.; Renaud, J.; Berinstain, A. B.; Scaiano, J. C. Can. J. Chem. 1995, 73, 223.

(24) Light induced homolysis of phenacyl halides: (a) McGimpsey, W. G.; Scaiano, J. C. Can. J. Chem. 1988, 66, 1474. (b) Renaud, J.; Scaiano, J. C. Can. J. Chem. 1996, 74, 1724. (c) Connolly, T. J.; Baldoví, M. V.; Mohtat, N.; Scaiano, J. C. Tetrahedron Lett. 1996, 37, 4919.

(25) In this scenario, radical anion 47 abstracts an I atom from another molecule of iodoacetophenone, generating radical 46 and an $\alpha$-iodo boronate complex, which is expected to undergo 1,2-migration rapidly to afford product $\mathbf{1 7}$. See ref 11 .

(26) (a) Studer, A.; Curran, D. P. Nat. Chem. 2014, 6, 765. (b) Studer, A.; Curran, D. P. Angew. Chem., Int. Ed. 2016, 55, 58.

(27) Odachowski, M.; Bonet, A.; Essafi, S.; Conti-Ramsden, P.; Harvey, J. N.; Leonori, D.; Aggarwal, V. K. J. Am. Chem. Soc. 2016, 138, 9521. 